\title{
Checkliste für das Vorstellungsgespräch
}

Hier findest du in kompakter und zusammengefasster Form die wichtigsten und formal zu beachtende Punkte als Checkliste zusammengefasst:

o Plane ausreichend Zeitpuffer für eine entspannte Anreise ein.

$\circ$ Nimm Kleingeld mit (z. B. für ein Taxi).

- Achte auf eine angemessene sowie unterwegs auf eine saubere Kleidung.

- Achte bei Dingen wie Jacke, Schal und Tasche darauf, dass du sie ohne großen Aufwand beiseitelegen kannst.

$\circ$ Nimm sicherheitshalber eine Kopie deiner Bewerbung mit.

o Nimm etwas zu schreiben mit, um dir ggf. Namen, Termine oder Fragen notieren zu können. Am besten hast du dafür eigens ein schickes Notizheft oder eine Businessmappe angeschafft.

- Nimm das Einladungsanschreiben mit, damit du Namen und Telefonnummern sowie mögliche Informationen (z. B. Etage und Nummer des Raums) sofort griffbereit hast.

- Sei nicht unterzuckert oder hungrig, wenn es losgeht.

○ Nimm kurz vorher ein Pfefferminzbonbon.

○ Achte auf trockene Hände bei der persönlichen Begrüßung.

o Nimm ein Getränk an, wenn es dir angeboten wird.

○ Halte Augenkontakt zu allen Gesprächspartnern.

$\circ$ Achte auf eine ruhige Körpersprache und Stimme.

- Recherchiere die wichtigsten Fakten über das Unternehmen und dessen Branche.

○ Bleibe entspannt und selbstbewusst, auch bei stressigen Fragen.

\section{Tipp}

Die Zauberformel für gelungene Vorstellungsgespräche besteht im Wesentlichen aus der fachlichen und mentalen Vorbereitung sowie aus zielführenden Kommunikations- und Präsentationstechniken. 